\title{
Body mass index and cardiovascular mortality at different levels of blood pressure: a prospective study of Norwegian men and
} women

\author{
Randi Selmer, Aage Tverdal
}

\begin{abstract}
Study objective - The study investigated the joint effect of body mass index and systolic blood pressure on cardiovascular and total mortality.

Design - This was a prospective cohort study. The main outcome measures were age adjusted mortality and relative risks estimated from survival models.
\end{abstract}

Setting - The population of the city of Bergen, Norway.

Participants - Subjects were 21145 men and 30330 women aged 30-79 years at the time of examination in 1963.

Main results - Both cause specific and all cause mortality increased with systolic blood pressure within each category of body mass index. Stroke mortality was not significantly associated with body mass index when adjusted for systolic blood pressure in either age group of men or women. Coronary heart disease mortality increased on average $30 \%$ per $5 \mathrm{~kg} / \mathrm{m}^{2}$ increase in body mass index in men and women aged 30-59 years at baseline. Adjusted for systolic blood pressure, the relative risks were reduced to $1.20(95 \%$ confidence interval $(\mathrm{CI}) 1 \cdot 12,1 \cdot 29)$ in men and $1 \cdot 10(95 \%$ CI $1 \cdot 03,1 \cdot 18)$ in women. They were similar at each level of systolic blood pressure. For coronary heart disease mortality in men and women aged 60-79 years at measurement a negative interaction between body mass index and systolic blood pressure was suggested in the first five years. Excluding the first five years, adjusted relative risks per $5 \mathrm{~kg} / \mathrm{m}^{2}$, were $1.05(95 \%$ CI $0 \cdot 96,1 \cdot 15)$ in men and $1 \cdot 11(95 \%$ CI $1 \cdot 04,1 \cdot 17)$ in women in the older age group. There was an upturn in cardiovascular mortality at low levels of body mass index in both age groups of women, but not in men.

Conclusions - Hypertension is an important risk factor for cardiovascular and all cause mortality even in the obese. Body mass index is generally a weak predictor of cardiovascular mortality in this population. It is a stronger risk factor of coronary death in men when measured at a younger age. Thin people with hypertension are not at particularly high risk of death from coronary heart disease compared with their obese counterparts, except possibly in the first few years after measurement in the elderly. Being underweight is associated with increased risk of death from all cardiovascular causes in women, but not in men.

\section{(F Epidemiol Community Health 1995;49:265-270)}

In 1959 it was first shown that being overweight is associated with an increased risk of death from cardiovascular disease. ${ }^{1}$ Weight is also correlated to blood pressure. One important question is whether weight is associated with cardiovascular mortality independent of blood pressure. It has been suggested that lean people with hypertension are at higher risk of cardiovascular mortality than their overweight/obese counterparts, ${ }^{2-5}$ and even that the positive association between blood pressure and cardiovascular mortality disappeared in the obese. ${ }^{2}$ There is still controversy, however, about this question. ${ }^{67}$ The studies were mainly based on results in men. We present results from a large follow up study of both men and women ranging in age from 30-79 years in 1963 when they were examined in the city of Bergen, Norway. The end points studied are death from stroke, coronary heart disease, all cardiovascular causes, and all causes.

\section{Methods}

In 1963 all people aged 14 years or more were invited to a compulsory mass miniature $x$ ray screening for pulmonary tuberculosis in the city of Bergen, Norway. A blood pressure survey was also carried out in connection with screening. ${ }^{89}$ Systolic and diastolic blood pressures were measured as well as weight and height. The present analyses are restricted to men and women aged $30-79$ years at the time of examination, who were alive on 1 January 1964 and for whom measurements of weight and height are available. There were 21145 men $(74 \%$ of the invited population) and 30330 women ( $86 \%$ of the invited population). The numbers in some of the tables may be slightly lower because some observations were missing for some of the participants.

Systolic and diastolic blood pressure were measured twice using a standard mercury sphygmomanometer and the lowest measurements were recorded. Cuffs that were $14 \mathrm{~cm}$ wide and $40 \mathrm{~cm}$ long were used throughout. Systolic blood pressure was defined as $\mathrm{mmHg}$ 

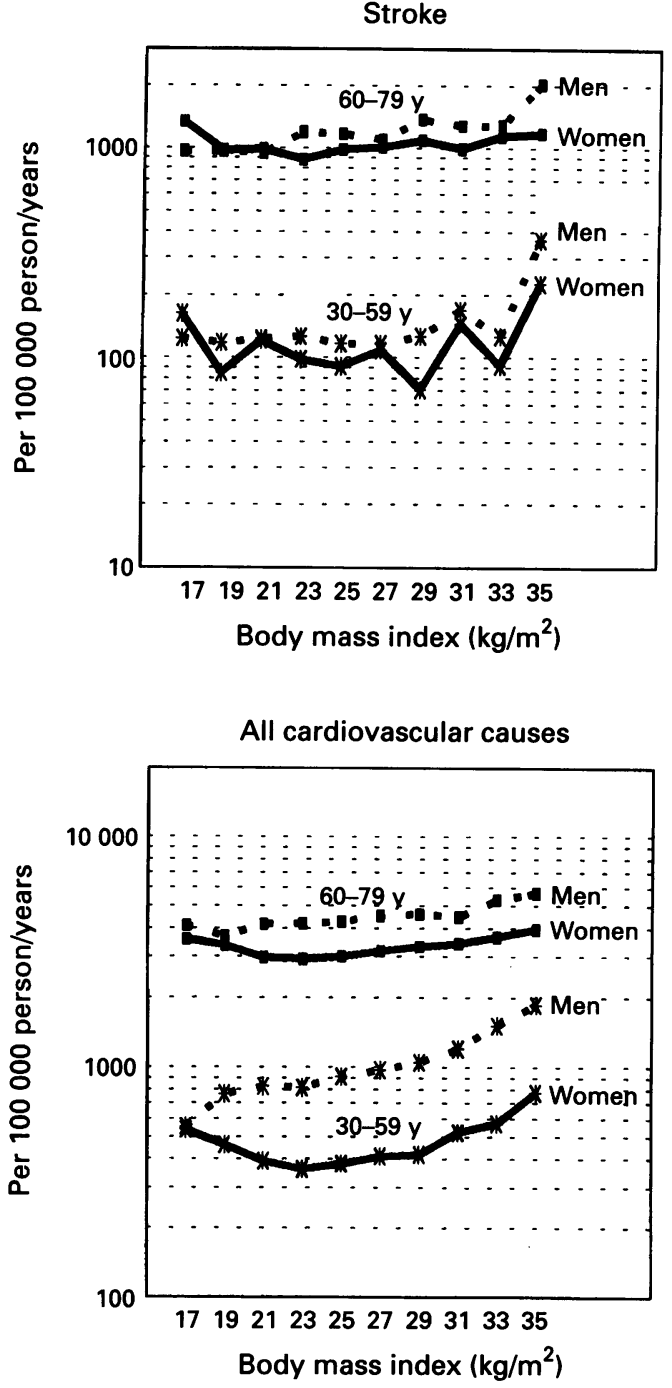

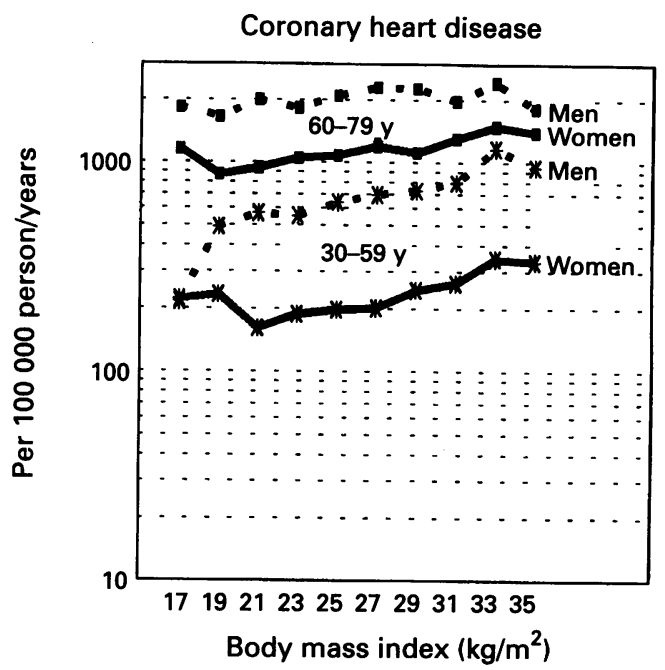

All causes

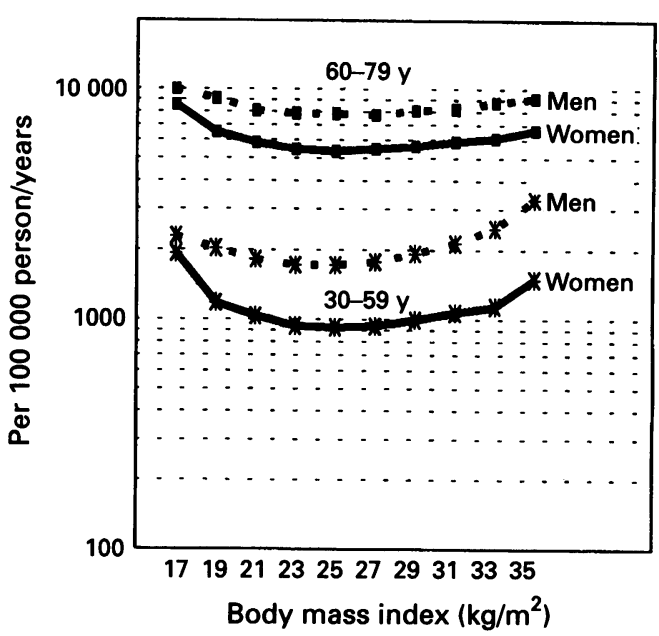

Age adjusted mortality rates in relation to body mass index in men and women aged 30-59 years and 60-79 years at baseline: The Bergen study 1963-90.

at the first Korotkoff sound (phase 1), diastolic blood pressure as $\mathrm{mmHg}$ at the disappearance of the Korotkoff sounds (phase 5).

The population has been followed with regard to death for 27 years. All dates of death and emigration from Norway and all codes for cause of death were obtained from the Norwegian Central Bureau of Statistics and no attempt has been made to change this. The official underlying cause of death according to the 7th, 8th, and 9th revisions of the International Classification of Diseases (ICD-7, ICD-8, and ICD-9) was used. Coronary heart disease was defined as ICD-7 code 420 (ICD8 codes $410,411,412 \cdot 0-412 \cdot 3,413$ and correspondingly ICD-9 codes $410-413,414 \cdot 0$ $414 \cdot 1,414 \cdot 9$ ), stroke as ICD-7 331-334 (ICD8 and ICD-9 codes 431-438) and all cardiovascular causes as ICD-7 codes 330-334, 400468 (ICD-8 390-458 and ICD-9 390-459).

Weight and height were measured and body mass index (weight/height $\left(\mathrm{kg} / \mathrm{m}^{2}\right)$ ) was computed.

Age adjusted mortality rates were calculated. The cut off points used in the grouped analysis were the first and fourth quintile of the distribution of body mass index and systolic blood pressure. The relative increase in mortality per
$5 \mathrm{~kg} / \mathrm{m}^{2}$ increase in body mass index was estimated using Cox's survival model. This corresponds to a weight difference of $15 \mathrm{~kg}$ in someone who is $1.73 \mathrm{~m}$ high. Inclusion of a quadratic term was also tested and the Cox model was used to estimate and test the combined influence of blood pressure, body mass index, and their interaction on mortality. To test the hypothesis of a different short term and long term association between body mass index and coronary heart disease mortality, survival models with interaction between time interval and body mass index were estimated using Poisson regression. The statistical software Epicure was used for these calculations. ${ }^{10}$ Inference was based on likelihood ratio tests.

\section{Results}

CARDIOVASCULAR AND TOTAL MORTALITY BY BODY MASS INDEX

Stroke mortality was only weakly associated with body mass index (figure, table 1 ). There was an upturn at low levels of body mass index in both age groups of women in whom inclusion of a quadratic term also improved the fit of the models $(p<0 \cdot 01)$. The relative risk per $5 \mathrm{~kg} /$ $\mathrm{m}^{2}$ was greater in women when measured at 
Table 1 Relative risk (95\% CI) of death from stroke, coronary heart disease, and all cardiovascular causes per $5 \mathrm{~kg} / \mathrm{m}^{2}$ increase in body mass index adjusted for age by Cox's survival model. The Bergen study 1963-90.

\begin{tabular}{llllll}
\hline Cause of death & $\begin{array}{l}\text { Men } \\
\text { Age }(y)\end{array}$ & & \multicolumn{3}{l}{$\begin{array}{l}\text { Women } \\
\text { Age }(y)\end{array}$} \\
\cline { 2 - 3 } \cline { 5 - 6 } \cline { 5 - 6 } & $30-59$ & $60-79$ & & $30-59$ & $60-79$ \\
\hline Stroke & $1 \cdot 14$ & $1 \cdot 17$ & & $1 \cdot 22$ & $1 \cdot 11$ \\
Coronary heart & $(0 \cdot 97,1 \cdot 35)$ & $(1 \cdot 06,1 \cdot 29)$ & & $(1 \cdot 11,1 \cdot 35)$ & $(1 \cdot 05,1 \cdot 18)$ \\
disease & $1 \cdot 30$ & $1 \cdot 10$ & & $1 \cdot 27$ & $1 \cdot 17$ \\
All cardiovascular & $(1 \cdot 21,1 \cdot 39)$ & $(1 \cdot 02,1 \cdot 18)$ & & $(1 \cdot 19,1 \cdot 36)$ & $(1 \cdot 11,1 \cdot 23)$ \\
causes & $1 \cdot 27$ & $1 \cdot 10$ & & $1 \cdot 26$ & $1 \cdot 13$ \\
& $(1 \cdot 20,1 \cdot 35)$ & $(1 \cdot 05,1 \cdot 16)$ & & $(1 \cdot 20,1 \cdot 32)$ & $(1 \cdot 09,1 \cdot 16)$ \\
\hline
\end{tabular}

Table 2 Relative risk (95\% CI) of death from coronary heart disease per $5 \mathrm{~kg} / \mathrm{m}^{2}$ increase in body mass index adjusted for age by Cox's survival model in different intervals of follow up. The Bergen study 1963-90.

\begin{tabular}{llllll}
\hline Time interval $(y)$ & $\begin{array}{l}\text { Men } \\
\text { Age }(y)\end{array}$ & & \multicolumn{3}{l}{$\begin{array}{l}\text { Women } \\
\text { Age }(y)\end{array}$} \\
\cline { 2 - 3 } \cline { 5 - 6 } \cline { 5 - 6 } & $30-59$ & $60-79$ & & $30-59$ & $60-79$ \\
\hline $0-5$ & $1 \cdot 23$ & $1 \cdot 03$ & & $1 \cdot 14$ & $1 \cdot 02$ \\
& $(0 \cdot 97,1 \cdot 56)$ & $(0 \cdot 90,1 \cdot 18)$ & & $(0 \cdot 79,1 \cdot 63)$ & $(0 \cdot 89,1 \cdot 17)$ \\
$5-15$ & $1 \cdot 32$ & $1 \cdot 19$ & & $1 \cdot 40$ & $1 \cdot 22$ \\
& $(1 \cdot 17,1 \cdot 49)$ & $(1 \cdot 07,1 \cdot 32)$ & & $(1 \cdot 23,1 \cdot 59)$ & $(1 \cdot 13,1 \cdot 32)$ \\
$15-27$ & $1 \cdot 29$ & $0 \cdot 99$ & & $1 \cdot 24$ & $1 \cdot 18$ \\
& $(1 \cdot 18,1 \cdot 41)$ & $(0 \cdot 84,1 \cdot 17)$ & & $(1 \cdot 15,1 \cdot 34)$ & $(1 \cdot 09,1 \cdot 28)$ \\
\hline
\end{tabular}

younger age but was almost the same in the two age groups of men.

Body mass index is a positive predictor of coronary heart disease mortality in men and women aged 30-59 years (figure, table 1). The risk increased on average by $30 \%$ per $5 \mathrm{~kg}$ / $\mathrm{m}^{2}$. In the older groups the relative risks were smaller. There was an upturn at the lowest level of body mass index in women, but inclusion of a quadratic term did not improve the fit of the survival models.

The relative increase per $5 \mathrm{~kg} / \mathrm{m}^{2}$ in body mass index was almost the same for all cardiovascular causes as for coronary heart disease mortality. There is a clear upturn in cardiovascular mortality at low levels of body mass index in both age groups of women and inclusion of a quadratic term improved the fit of the models in these groups $(p<0.0001)$.

The association between body mass index and all cause mortality is clearly $U$ shaped in all groups, with the optimal value around $25 \mathrm{~kg}$ / $\mathrm{m}^{2}$.

To study the effect of time since examination, we divided the follow up period into three time intervals - the first five years, the next 10

Table 3 Age adjusted, 27 year mortality rates (per 100000 people/year) in relation to the distribution of body mass index (BMI) and systolic blood pressure (in fifths $\left(Q_{1}-Q_{5}\right)$ ) for men and women aged 30-59 years at baseline. The Bergen study, $1963-90$.

\begin{tabular}{|c|c|c|c|c|c|c|c|c|c|c|c|c|c|c|}
\hline \multirow{3}{*}{$\begin{array}{l}\text { Cause of death } \\
\text { Distribution of systolic } \\
\text { blood pressure }\end{array}$} & \multicolumn{6}{|c|}{$\begin{array}{l}\text { Men } \\
\text { Distribution of } B M I\end{array}$} & \multirow[t]{3}{*}{$\begin{array}{l}\text { Rate ratio } \\
Q_{5} / Q_{1}\end{array}$} & \multicolumn{6}{|c|}{$\begin{array}{l}\text { Women } \\
\text { Distribution of } B M I\end{array}$} & \multirow[t]{3}{*}{$\begin{array}{l}\text { Rate ratio } \\
Q_{s} / Q_{1}\end{array}$} \\
\hline & \multicolumn{2}{|c|}{$\operatorname{Low}\left(Q_{\nu}\right)$} & \multicolumn{2}{|c|}{ Middle $\left(Q_{2}-Q_{1}\right)$} & \multicolumn{2}{|c|}{$\operatorname{High}\left(Q_{s}\right)$} & & \multicolumn{2}{|c|}{$\operatorname{Low}\left(Q_{\nu}\right)$} & \multicolumn{2}{|c|}{ Middle $\left(Q_{2}-Q_{1}\right)$} & \multicolumn{2}{|c|}{$\operatorname{High}\left(Q_{s}\right)$} & \\
\hline & No & Rate & No & Rate & No & Rate & & No & Rate & No & Rate & No & Rate & \\
\hline $\begin{array}{l}\text { Stroke } \\
\text { Low }\left(Q_{1}\right) \\
\text { Middle }\left(Q_{2}-Q_{4}\right) \\
\text { High }\left(Q_{5}\right) \\
\text { Rate ratio }\left(Q_{5} / Q_{1}\right) \\
\text { Compry heart disease }\end{array}$ & $\begin{array}{l}11 \\
33 \\
23\end{array}$ & $\begin{array}{r}98 \cdot 9 \\
102 \cdot 1 \\
172 \cdot 0 \\
1 \cdot 74\end{array}$ & $\begin{array}{r}26 \\
109 \\
95\end{array}$ & $\begin{array}{r}96 \cdot 7 \\
94 \cdot 0 \\
191 \cdot 5 \\
1 \cdot 98\end{array}$ & $\begin{array}{r}5 \\
46 \\
60\end{array}$ & $\begin{array}{r}79 \cdot 6 \\
102 \cdot 0 \\
206 \cdot 1 \\
2 \cdot 59\end{array}$ & $\begin{array}{l}0 \cdot 80 \\
1 \cdot 00 \\
1 \cdot 20\end{array}$ & $\begin{array}{r}6 \\
37 \\
20\end{array}$ & $\begin{array}{r}50 \cdot 7 \\
106 \cdot 0 \\
170 \cdot 2 \\
3 \cdot 36\end{array}$ & $\begin{array}{r}23 \\
141 \\
129\end{array}$ & $\begin{array}{r}75 \cdot 8 \\
82 \cdot 5 \\
136 \cdot 6 \\
1 \cdot 80\end{array}$ & $\begin{array}{r}2 \\
40 \\
131\end{array}$ & $\begin{array}{r}37 \cdot 0 \\
61 \cdot 8 \\
184 \cdot 6 \\
4 \cdot 99\end{array}$ & $\begin{array}{l}0.73 \\
0.58 \\
1.08\end{array}$ \\
\hline $\begin{array}{l}\text { Low }\left(\mathrm{Q}_{1}\right) \\
\text { Middle }\left(\mathrm{Q}_{2}-\mathrm{Q}_{4}\right) \\
\text { High }\left(\mathrm{Q}_{5}\right) \\
\text { Rate ratio }\left(\mathrm{Q}_{5} / \mathrm{Q}_{1}\right) \\
\text { All causes }\end{array}$ & $\begin{array}{r}44 \\
177 \\
93\end{array}$ & $\begin{array}{r}343 \cdot 8 \\
522 \cdot 0 \\
786 \cdot 6 \\
2 \cdot 29\end{array}$ & $\begin{array}{l}128 \\
676 \\
380\end{array}$ & $\begin{array}{r}416 \cdot 2 \\
556 \cdot 8 \\
860 \cdot 2 \\
2 \cdot 07\end{array}$ & $\begin{array}{r}38 \\
282 \\
245\end{array}$ & $\begin{array}{r}566 \cdot 4 \\
647 \cdot 7 \\
992 \cdot 3 \\
1 \cdot 75\end{array}$ & $\begin{array}{l}1 \cdot 65 \\
1 \cdot 24 \\
1 \cdot 26\end{array}$ & $\begin{array}{l}18 \\
72 \\
30\end{array}$ & $\begin{array}{r}122 \cdot 3 \\
186 \cdot 2 \\
272 \cdot 3 \\
2 \cdot 23\end{array}$ & $\begin{array}{r}42 \\
297 \\
245\end{array}$ & $\begin{array}{r}118 \cdot 2 \\
167 \cdot 6 \\
284 \cdot 7 \\
2 \cdot 41\end{array}$ & $\begin{array}{r}6 \\
118 \\
245\end{array}$ & $\begin{array}{r}106 \cdot 4 \\
187 \cdot 3 \\
385 \cdot 9 \\
3 \cdot 63\end{array}$ & $\begin{array}{l}0 \cdot 87 \\
1 \cdot 01 \\
1 \cdot 42\end{array}$ \\
\hline $\begin{array}{l}\text { Low }\left(Q_{1}\right) \\
\text { Middle }\left(Q_{2}-Q_{4}\right) \\
\text { High }\left(Q_{5}\right) \\
\text { Rate ratio }\left(Q_{5} / Q_{1}\right)\end{array}$ & $\begin{array}{l}192 \\
610 \\
293\end{array}$ & $\begin{array}{r}1531 \cdot 7 \\
1807 \cdot 5 \\
2437 \cdot 8 \\
1 \cdot 59\end{array}$ & $\begin{array}{r}433 \\
1931 \\
989\end{array}$ & $\begin{array}{r}1431 \cdot 8 \\
1598 \cdot 1 \\
2207 \cdot 4 \\
1 \cdot 54\end{array}$ & $\begin{array}{l}100 \\
762 \\
600\end{array}$ & $\begin{array}{r}1518 \cdot 3 \\
1740 \cdot 7 \\
2375 \cdot 3 \\
1 \cdot 56\end{array}$ & $\begin{array}{l}0.99 \\
0.96 \\
0.97\end{array}$ & $\begin{array}{l}172 \\
454 \\
151\end{array}$ & $\begin{array}{r}998 \cdot 4 \\
1085 \cdot 6 \\
1426 \cdot 8 \\
1 \cdot 43\end{array}$ & $\begin{array}{r}304 \\
1552 \\
932\end{array}$ & $\begin{array}{r}777 \cdot 0 \\
863 \cdot 2 \\
1159 \cdot 6 \\
1 \cdot 49\end{array}$ & $\begin{array}{r}44 \\
555 \\
828\end{array}$ & $\begin{array}{r}781 \cdot 2 \\
895 \cdot 7 \\
1408 \cdot 5 \\
1 \cdot 80\end{array}$ & $\begin{array}{l}0 \cdot 78 \\
0 \cdot 83 \\
0 \cdot 99\end{array}$ \\
\hline
\end{tabular}

Table 4 Age adjusted, 27 year mortality rates (per 100000 people per year) in relation to the distribution of body mass index (BMI) and systolic blood pressure (in fifths $\left(Q_{1}-Q_{s}\right)$ ) in men and women aged 60-79 years at baseline. The Bergen study, $1963-90$.

\begin{tabular}{|c|c|c|c|c|c|c|c|c|c|c|c|c|c|c|}
\hline \multirow{3}{*}{$\begin{array}{l}\text { Cause of death } \\
\text { Distribution of systolic } \\
\text { blood pressure }\end{array}$} & \multicolumn{6}{|c|}{$\begin{array}{l}\text { Men } \\
\text { Distribution of BMI }\end{array}$} & \multirow[t]{3}{*}{$\begin{array}{l}\text { Rate ratio } \\
Q_{5} / Q_{1}\end{array}$} & \multicolumn{6}{|c|}{$\begin{array}{l}\text { Women } \\
\text { Distribution of BMI }\end{array}$} & \multirow[t]{3}{*}{$\begin{array}{l}\text { Rate ratio } \\
Q_{s} / Q_{t}\end{array}$} \\
\hline & \multicolumn{2}{|c|}{$\operatorname{Low}\left(Q_{\nu}\right)$} & \multicolumn{2}{|c|}{ Middle $\left(Q_{2}-Q_{1}\right)$} & \multicolumn{2}{|c|}{$\operatorname{High}\left(Q_{s}\right)$} & & \multicolumn{2}{|c|}{ Low $\left(Q_{\nu}\right)$} & \multicolumn{2}{|c|}{ Middle $\left(Q_{2}-Q_{1}\right)$} & \multicolumn{2}{|c|}{$\operatorname{High}\left(Q_{s}\right)$} & \\
\hline & No & Rate & No & Rate & No & Rate & & No & Rate & No & Rate & No & Rate & \\
\hline $\begin{array}{l}\text { Stroke } \\
\text { Low }\left(Q_{1}\right) \\
\text { Middle }\left(Q_{2}-Q_{4}\right) \\
\text { High }\left(Q_{5}\right) \\
\text { Rate ratio }\left(Q_{5} / Q_{1}\right) \\
\text { Coronary heart disease }\end{array}$ & $\begin{array}{l}32 \\
80 \\
32\end{array}$ & $\begin{array}{r}832 \cdot 4 \\
892 \cdot 2 \\
1678 \cdot 0 \\
2 \cdot 02\end{array}$ & $\begin{array}{r}71 \\
325 \\
136\end{array}$ & $\begin{array}{r}828 \cdot 2 \\
1081 \cdot 2 \\
1727 \cdot 6 \\
2 \cdot 09\end{array}$ & $\begin{array}{r}21 \\
119 \\
76\end{array}$ & $\begin{array}{r}981 \cdot 4 \\
1173 \cdot 3 \\
2158 \cdot 5 \\
2 \cdot 20\end{array}$ & $\begin{array}{l}1 \cdot 18 \\
1 \cdot 32 \\
1 \cdot 29\end{array}$ & $\begin{array}{r}72 \\
163 \\
49\end{array}$ & $\begin{array}{r}903.3 \\
902 \cdot 2 \\
1450 \cdot 9 \\
1 \cdot 61\end{array}$ & $\begin{array}{l}129 \\
565 \\
246\end{array}$ & $\begin{array}{r}733.9 \\
923.9 \\
1488.3 \\
2.03\end{array}$ & $\begin{array}{r}17 \\
194 \\
125\end{array}$ & $\begin{array}{r}508 \cdot 6 \\
1056 \cdot 5 \\
1581 \cdot 6 \\
3 \cdot 11\end{array}$ & $\begin{array}{l}0.56 \\
1.17 \\
1.09\end{array}$ \\
\hline $\begin{array}{l}\text { Low }\left(Q_{1}\right) \\
\text { Middle }\left(Q_{2}-Q_{4}\right) \\
\text { High }\left(Q_{5}\right) \\
\text { Rate ratio }\left(Q_{5} / Q_{1}\right) \\
\text { All causes }\end{array}$ & $\begin{array}{r}47 \\
166 \\
64\end{array}$ & $\begin{array}{r}1180 \cdot 7 \\
1860 \cdot 4 \\
3679 \cdot 9 \\
3 \cdot 12\end{array}$ & $\begin{array}{l}131 \\
612 \\
226\end{array}$ & $\begin{array}{r}1416 \cdot 5 \\
2016 \cdot 6 \\
3106 \cdot 9 \\
2 \cdot 19\end{array}$ & $\begin{array}{r}31 \\
217 \\
90\end{array}$ & $\begin{array}{r}1424 \cdot 0 \\
2161 \cdot 4 \\
2730 \cdot 4 \\
1 \cdot 92\end{array}$ & $\begin{array}{l}1 \cdot 21 \\
1 \cdot 16 \\
0 \cdot 74\end{array}$ & $\begin{array}{r}61 \\
172 \\
54\end{array}$ & $\begin{array}{r}701 \cdot 3 \\
991 \cdot 3 \\
1906 \cdot 7 \\
2 \cdot 72\end{array}$ & $\begin{array}{l}153 \\
661 \\
247\end{array}$ & $\begin{array}{r}779 \cdot 4 \\
1089 \cdot 4 \\
1624 \cdot 3 \\
2 \cdot 08\end{array}$ & $\begin{array}{r}27 \\
254 \\
136\end{array}$ & $\begin{array}{r}742 \cdot 5 \\
1360 \cdot 0 \\
1795 \cdot 3 \\
2 \cdot 42\end{array}$ & $\begin{array}{l}1.06 \\
1.37 \\
0.94\end{array}$ \\
\hline $\begin{array}{l}\text { Low }\left(Q_{1}\right) \\
\text { Middle }\left(Q_{2}-Q_{4}\right) \\
\text { High }\left(Q_{5}\right) \\
\text { Rate ratio }\left(Q_{5} / Q_{1}\right)\end{array}$ & $\begin{array}{l}297 \\
742 \\
195\end{array}$ & $\begin{array}{r}7607 \cdot 9 \\
8285 \cdot 2 \\
10778 \cdot 8 \\
1 \cdot 42\end{array}$ & $\begin{array}{r}618 \\
2261 \\
755\end{array}$ & $\begin{array}{r}6916 \cdot 2 \\
7471 \cdot 6 \\
9983 \cdot 2 \\
1 \cdot 44\end{array}$ & $\begin{array}{l}136 \\
794 \\
347\end{array}$ & $\begin{array}{r}6367 \cdot 7 \\
7904 \cdot 2 \\
10153 \cdot 0 \\
1 \cdot 59\end{array}$ & $\begin{array}{l}0.84 \\
0.95 \\
0.94\end{array}$ & $\begin{array}{r}444 \\
1030 \\
260\end{array}$ & $\begin{array}{r}5383 \cdot 8 \\
5772 \cdot 8 \\
8226 \cdot 2 \\
1 \cdot 53\end{array}$ & $\begin{array}{r}859 \\
3248 \\
1119\end{array}$ & $\begin{array}{r}4671 \cdot 2 \\
5326 \cdot 8 \\
6993 \cdot 1 \\
1 \cdot 50\end{array}$ & $\begin{array}{r}164 \\
1117 \\
567\end{array}$ & $\begin{array}{r}4740 \cdot 8 \\
6049 \cdot 1 \\
7325 \cdot 3 \\
1 \cdot 55\end{array}$ & $\begin{array}{l}0.88 \\
1.05 \\
0 \cdot 89\end{array}$ \\
\hline
\end{tabular}


years, and the last 12 years. Survival models for coronary heart disease mortality, with and without an interaction term between time interval and body mass index, were estimated. Introducing interaction terms into the models did not improve the fit significantly in either group. In the first five years there was no significant positive association between body mass index and coronary heart disease mortality (table 2).

\section{JOINT EFFECT OF BODY MASS INDEX AND} SYSTOLIC BLOOD PRESSURE ON CARDIOVASCULAR AND TOTAL MORTALITY

Both total and cardiovascular mortality increased with increasing systolic blood pressure at all levels of body mass index in all groups (tables 3 and 4).

Stroke mortality varied very little with body mass index within the categories of systolic blood pressure. When adjusted for systolic blood pressure using Cox's survival model the associations turned out to be non-significant in all groups of men and women.

Coronary heart disease mortality was weakly but positively associated with body mass index at all levels of systolic blood pressure in men aged 30-59 years (table 3 ). The relative risk per $5 \mathrm{~kg} / \mathrm{m}^{2}$, adjusted for age, time, and systolic blood pressure by Cox's survival model, was estimated to be $1 \cdot 20$ ( $95 \%$ confidence interval (CI) $1 \cdot 12,1 \cdot 29)$. In women aged $30-59$ years the adjusted relative risk was $1 \cdot 10(95 \% \mathrm{CI}$ $1 \cdot 03,1 \cdot 18)$. Introducing an interaction term between body mass index and systolic blood pressure in Cox's survival model did not improve the fit in either the women or men who were 30-59 years at baseline.

In men and women aged 60-79 years at baseline the thinnest group with the highest systolic blood pressure had the highest mortality from coronary heart disease (table 4). Although weak, a negative interaction is suggested. Separate analyses for the first five years of follow up suggested a negative interaction in the first period $(p=0.05$ in men and $p=$ 0.07 in women) but not in the rest of follow up. When the first five years were excluded the adjusted relative risk of death from coronary heart disease per $5 \mathrm{~kg} / \mathrm{m}^{2}$ was only $1.05(95 \%$ CI $0 \cdot 96,1 \cdot 15)$ in the men and $1 \cdot 11(95 \%$ CI $1 \cdot 04,1 \cdot 17)$ in the women aged $60-79$ years at baseline.

The association between mortality from all cardiovascular causes and body mass index is more $U$ shaped in women than in men within each category of systolic blood pressure. Using Cox's survival model, with systolic blood pressure and age included as continuous variables and body mass index as dummy variables, we estimated that women in the thinnest fifth of the distribution had an adjusted relative risk of cardiovascular death of $1.12(95 \%$ CI 1.04 , $1 \cdot 21$ ) compared with the middle group. Correspondingly, in women 60-79 years, the adjusted relative risk was 1.25 (95\% CI 1.09 , 1.43).

An upturn in total mortality at low levels of body mass index is seen in all categories of systolic blood pressure in both men and women of all ages.

\section{Discussion}

Systolic blood pressure was a positive predictor of stroke mortality at all levels of body mass index. The association between body mass index and stroke mortality was, however, weak in this study and disappeared when adjusting for systolic blood pressure. The association seems to be somewhat weaker than in another Norwegian study in which an increased risk at low levels of body mass index was also seen. ${ }^{11}$ The small number of observations in the category with the lowest body mass index in our study make the results inconclusive. A stronger effect of body mass index on stroke mortality was also found in a 26 year follow up of the Framingham heart study in women but not in men. ${ }^{12}$ Previous results from the Whitehall study ${ }^{13}$ showed that the relationship between body mass index and stroke mortality was stronger in non-smokers than in smokers and ex-smokers, and stronger when examined at younger ages. In 1963 the percentage of the Norwegian population that smoked regularly varied from $5 \%$ in women aged $70-75$ years to around $40 \%$ in women aged $30-35$ years and from $40 \%$ in men aged $70-75$ years to around $65 \%$ in men aged $30-35$ years. ${ }^{14}$ Thus failure to adjust for smoking may be part of the explanation of the weak association between obesity and stroke mortality in men and in younger women in Bergen. With respect to age at examination, there is no consistent pattern. In the female population in Bergen the greatest relative risk was found in the youngest group. In men the relative risks were almost the same in both age groups and the confidence intervals overlapped substantially.

Systolic blood pressure is a strong predictor of coronary heart disease mortality at all levels of body mass index in all age groups of both men and women. The positive relationship between systolic blood pressure and the risk of coronary heart disease mortality did not disappear in the obese. Thus the results from this study do not support the hypothesis that blood pressure does not predict coronary heart disease mortality in the obese as demonstrated in a study in California. ${ }^{2}$ The confidence intervals for the relative risks associated with systolic blood pressure among lean and obese people overlapped substantially in that study, however, and a test for interaction was not presented. Other studies of the joint effect of blood pressure and body mass index show varying results. The studies of Cambien $\mathrm{et} \mathrm{al}^{3}$ the Israeli ischemic heart disease study, ${ }^{4}$ and the Whitehall study ${ }^{5}$ showed a negative interaction, as in the California study, but obese hypertensive subjects were still at increased risk of cardiovascular death compared with obese patients with normal blood pressure. Data from the Honolulu heart programme ${ }^{6}$ and the British regional heart study, ${ }^{7}$ on the other hand, showed no interaction between blood pressure and body mass index in respect of the risk of cardiovascular disease. In the Bergen popu- 
lation there may be a weak negative interaction between systolic blood pressure and body mass index in the older age groups: the leanest group with the highest systolic blood pressure had the highest risk of death from coronary heart disease. The reason for the discrepancy between studies is unknown. But, the varying length of follow up may be of some importance. We did separate analyses for the first five years and the rest of follow up - an interaction was suggested for the first period, but not in the remainder. The presence of a negative interaction in the first five years in the older groups only suggests that coronary disease at baseline may explain some of the association. The results agree with data from Framingham. In an eight year follow up in Framingham it was suggested that lean hypertensives were at increased risk of cardiovascular death compared with obese hypertensives but this was not confirmed in the 26 year follow up ${ }^{12}$ or the 34 year follow up. ${ }^{15}$ As in our study, people with heart disease at baseline were not excluded. This may explain the different results with different lengths of follow up. An 8.9 year follow up of another Norwegian population, aged 35-49 years at baseline, suggested that the association between blood pressure and risk of coronary death was much weaker in very obese men. ${ }^{16}$ The number of men in the upper stratum of the body mass index range was small, however, and interaction was significant only in the age group 40-44 years.

The varying length of follow up may also explain why the strength of the association between body mass index and cardiovascular mortality differs between studies. It has been postulated that the effect of overweight may be evident only after longer periods of follow up. We investigated this by dividing the follow up period into three. There was no significant interaction between time interval and body mass index in either age group. Furthermore, there was no significant association between coronary heart disease mortality and body mass index in the first five years in either group. In the younger age group, the lack of significant associations in the first five years may be due to the small number of deaths in the first period.

Our results indicate that the relative risks of coronary heart disease mortality associated with obesity are higher when measured at a younger age in men, while this was not apparent in women. This was also a finding in the Framingham study. ${ }^{12}$ Different age distributions may therefore be one of the explanations of varying results between populations.

The correlation between body mass index and blood pressure varies with age and between populations. This may partly explain the discrepancy between studies. In our study the partial correlation between body mass index and systolic blood pressure adjusted for age was $0 \cdot 15$ in both age groups of men, while the values were 0.27 in women aged 30-59 years and 0.22 in women aged $60-79$ years. Thus, the results in men do not support the hypothesis that the correlations decline with advancing age. ${ }^{17}$ The correlations in men are similar to those reported in the California study. ${ }^{2}$ They were lower than in the Framingham study ${ }^{18}$ and the Honolulu heart study. ${ }^{6}$

Some populations are leaner than others. The range of body mass index may also vary between populations. If the heterogeneity in body mass index is small, there will be a weaker association with mortality than if there are more people at the extremes of the distribution. Also people with the same body mass index may have quite different body composition and thus have a different risk of coronary heart disease.

This study showed that lean women are at increased risk of death from cardiovascular disease independent of blood pressure. There was a parabolic association in women, but not in men. The reason for the different association in men and women is unknown. A possible explanation is that the higher oestrogen levels in obese compared with lean postmenopausal women protect against cardiovascular disease.

In this study there was a parabolic relationship between body mass index and total mortality at all levels of blood pressure. When the true association is $U$ shaped, different cut off points for definition of fatness-leanness influence the relative risks of lean versus fat hypertensives. ${ }^{19}$ In a 8.3 year follow up of the hypertension detection and follow-up program, cause specific mortality was analysed to explore the increased all cause mortality in lean hypertensives. ${ }^{20}$ The findings indicated that excess alcohol intake and smoking were important factors that contributed to the excess risk.

Blood pressure measurements are subject to measurement error. Using a cuff that is too small would lead to overestimation of blood pressure in the obese. The size of the cuff used in this study was sufficiently large to fit the fattest arms.

In this study hypertension was an important risk factor for cardiovascular mortality independent of body mass index. This may have important implications for blood pressure treatment in obese and lean people. Furthermore, lean hypertensives were not at particularly high risk of death from coronary heart disease compared with obese hypertensives, except possibly in the first few years after measurements in the elderly. The theory that weight reduction to lower blood pressure is not appropriate seems not to be justified. The finding of an upturn in cardiovascular mortality at low levels of body mass index in women, but not in men, warrants further investigation.

1 Metropolitan Life Insurance Company. Build and pressure study 1959. Vol I, II. Chicago: Society of Actuaries, 1960. 2 Barrett-Connor E, Kay-Tee K. Is hypertension more benign when associated with obesity? Circulation 1985;72:53-60. 3 Cambien F, Chretien JM, Ducimetiere P, Guize L, Richard $\pi$. Is the relationship between blood pressure and cardiovascular risk dependent on body mass index? $A m \mathcal{F} E p-$ idemiol 1985;122:434-42.

4 Goldbourt U, Holtzman E, Cohen-Mandelzweig L, Neufeld $\mathrm{HN}$. Enhanced risk of coronary heart disease in lean hypertensive men. Hypertension 1987;10:22-8.

5 Elliott P, Shipley MJ, Rose G. Are lean hypertensives at greater risk than obese hypertensives? $\mathcal{F}$ Hypertens 1987 ; 5(suppl 5):S517-9.

6 Bloom E, Dwayne R, Yano K, MacLean C. Does obesity protect hypertensives against cardiovascular disease? $A M A$ 1986;256:2972-5.

7 Phillips A, Shaper AG. Relative weight and major ischaemic heart disease events in hypertensive men. Lancet 1989;i: 1005-8.

8 Holme I, Waaler HT. Five-year mortality in the city of Bergen, Norway, according to age, sex and blood pressure. Acta Med Scand 1976;200:229-39. 
9 Selmer R. Blood pressure and twenty-year mortality in the city of Bergen, Norway. Am ₹ Epidemiol 1992;136:428-40. 10 Preston DI Lubin JH, Pierce DA, McConney ME. Epicure user's guide. Seattle: Hirosoft International Corporation, 1993.

11 Waaler HT. Height, weight and mortality. The Norwegian experience. Oslo: National Institute of Public Health, 1984 Report no 4.

12 Hubert HB, Feinleib M, McNamara PM, Castelli WP. Obesity as an independent factor for cardiovascular disease: A 26-year follow-up of participants in the Framingham heart study. Circulation 1983;67:968-77.

13 Shinton R, Shipley M, Rose G. Overweight and stroke in the Whitehall Study F Epidemiol Community Health 1991; 45:138-42.

14 Ranneberg A, Hafstad A, Lund KE. Lifetime smoking habits mong born been 1890 among Norwegian men and women born
15 Kannel WB, Zhang T, Garrison RJ. Is obesity-related hypertension less of a cardiovascular risk? The Framingham pertension less of a cardiovascular risk?

16 Tverdal A. Systolic and diastolic blood pressure as predictors of coronary heart disease in middle aged Norwegian men. 1987;294:671-3

17 Havlik RJ, Hubert HB, Fabitz RR, et al. Weight and hypertension. Ann Intern Med 1983;98:855-9.

18 Kannel WB, Brand N, Skinner JJ, et al. The relationship of adiposity to blood pressure and development of hypertension. Ann Intern Med 1967;67:48-59.

19 Menotti A, Giampaoli S, Pasquali M, Seccareccia F, Stuart K. Prognosis of lean and fat hypertensives. Cardiology 1988;75:448-57.

20 Stamler R, Ford CE, Stamler J. Why do lean hypertensives have higher mortality rates than other hypertensives? Findings from the hypertension detection and follow-up program. Hypertension 1991;17:553-64.

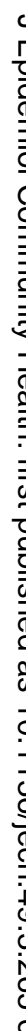

